\title{
Leveraging family dynamics to increase the effectiveness of incentives for physical activity: the FIT-FAM randomized controlled trial
}

Eric Andrew Finkelstein ${ }^{1 *}$ D, Robyn Su May Lim¹, Dianne Stanton Ward ${ }^{2,3}$ and Kelly R. Evenson ${ }^{2,4}$

\begin{abstract}
Background: Insufficient physical activity is a global public health concern. Research indicates incentives can increase physical activity levels of children but has not tested whether incentives targeted at children can be leveraged to increase physical activity levels of their parents. This study evaluates whether a novel incentive design linking children's incentives to both their and their parent's physical activity levels can increase parent's physical activity.

Methods: We conducted a two-arm, parallel, open-labelled randomized controlled trial in Singapore where parentchild dyads were randomly assigned to either (1) rewards to child contingent on child's physical activity (child-based)

or (2) rewards to child contingent on both child's and parent's physical activity (family-based). Parents had to be English-speaking, computer-literate, non-pregnant, full-time employees, aged 25-65 years, and with a participating child aged 7-11 years. Parent-child dyads were randomized within strata (self-reported low vs high weekly physical activity) into study arms in a 1:1 ratio. Participants were given activity trackers to assess daily steps. The outcome of interest was the between-arm difference in the change from baseline in parent's mean steps/day measured by accelerometry at months 6 and 12 (primary endpoint).
\end{abstract}

Results: Overall, 159 and 157 parent-child dyads were randomized to the child-based or family-based arms, respectively. Outcomes were evaluated on an intent-to-treat basis. At month 6, there was a 613 steps/day (95\% Cl: 541171) differential in favour of family-based parents. At month 12, our primary endpoint, the differential was reduced to 369 steps/day (95\% Cl: - 88-1114) and was no longer statistically significant.

Conclusions: Our findings suggest that novel incentive designs that take advantage of group dynamics may be effective. However, in this design, the effectiveness of the family-based incentive to increase parent's physical activity was not sustained through one year.

Trial registration: NCT02516345 (ClinicalTrials.gov) registered on August 5, 2015.

Keywords: Physical activity, Incentives, Group, Rewards, Randomized controlled trial, Activity tracker, Accelerometer, Parents, Children, Steps

\footnotetext{
* Correspondence: eric.finkelstein@duke-nus.edu.sg

'Programme in Health Services and Systems Research, Duke-NUS Medical

School, 8 College Road, Singapore 169857, Singapore

Full list of author information is available at the end of the article
}

\section{$\triangle B M C$}

(c) The Author(s). 2020 Open Access This article is licensed under a Creative Commons Attribution 4.0 International License, which permits use, sharing, adaptation, distribution and reproduction in any medium or format, as long as you give appropriate credit to the original author(s) and the source, provide a link to the Creative Commons licence, and indicate if changes were made. The images or other third party material in this article are included in the article's Creative Commons licence, unless indicated otherwise in a credit line to the material. If material is not included in the article's Creative Commons licence and your intended use is not permitted by statutory regulation or exceeds the permitted use, you will need to obtain permission directly from the copyright holder. To view a copy of this licence, visit http://creativecommons.org/licenses/by/4.0/ The Creative Commons Public Domain Dedication waiver (http://creativecommons.org/publicdomain/zero/1.0/) applies to the data made available in this article, unless otherwise stated in a credit line to the data. 


\section{Background}

There is overwhelming evidence that sustained physical activity reduces risks for non-communicable diseases, increases longevity, and reduces medical costs and productivity losses $[1,2]$. Yet, the prevalence of insufficient physical activity has been steadily rising in high income countries, from $31.6 \%$ in 2001 to $36.8 \%$ in 2016 [3]. This has translated into global annual costs of roughly $\$ 54$ billion and $\$ 14$ billion in medical expenditures and productivity losses, respectively [4]. Thus, governments, insurers, and employers alike share a common interest in increasing physical activity.

Despite the obvious health benefits, there are many barriers to engaging in physical activity. One framework to consider how much to exercise is through the lens of classical economic theory [5]. This theory assumes that individuals are rational and weigh the costs and benefits of their decisions, including the decision of how much to exercise. If the benefits of an additional unit of exercise outweigh the costs, then the individual is expected to engage in the physical activity, otherwise s/he will not. This theory posits that one way to increase physical activity is through the use of economic incentives. Incentives, by increasing the benefits, are expected to induce greater levels of physical activity. Moreover, this finding holds even in the presence of several common biases, such as present-bias where individuals place too much weight on the immediate costs of exercise and too little weight (from their future selves' perspective) on the potential health benefits that may not materialize until well into the future [6-8]. Consistent with these predictions, studies indicate that economic incentives can effectively increase physical activity in both children and adults [9-14].

Although studies have shown that incentives can be used to increase physical activity levels of the individual receiving the incentive, no studies to our knowledge have attempted to leverage incentives to increase physical activity of an affiliate, such as a close friend or family member, even if the affiliate is not a target of the incentive. Yet, economic theory further suggests this is possible if there is a cost, which need not be monetary, to the affiliate when the recipient does not obtain the reward and/or if the affiliate sees value in the recipient gaining the reward [15].

We tested this hypothesis using a two-arm, parallel, open-labelled randomized controlled trial (RCT) among child (recipient) and parent (affiliate) dyads. Focusing on child-parent dyads (term family-based) is appealing because children have been shown to increase physical activity levels even for relatively modest rewards [10] and because parents may be inclined to increase their physical activity levels both to not bear the "cost" of disappointing their child and because they value the increase in their child's physical activity levels. We hypothesized that, for the same step targets and incentive level, the family-based incentive scheme would be more effective at increasing parent's physical activity at months 6 and 12 (primary) than incentivizes that target children only (termed "child-based").

\section{Methods}

Study design, recruitment, and participant characteristics FIT-FAM (Financial Incentive Trial targeting FAMilies) was a 12-month (48-week), open-labelled RCT conducted in Singapore comparing two parallel arms (1:1 allocation ratio): (1) activity tracker plus child-based incentive, and (2) activity tracker plus family-based incentive. This manuscript conforms to CONSORT reporting guidelines (Additional file 1, CONSORT checklist).

Participants were recruited directly through advertisements and indirectly via "cold calls" to select companies. Ultimately, 5 private sector and 5 public sector companies agreed to participate and promote the study to their employees. All interested individuals recruited through the advertisements or from the company worksites were directed to the study website for additional information, registration, and eligibility screening, which was administered through an online questionnaire.

To be eligible, parents had to be English-speaking, computer-literate, non-pregnant, maintain full-time employment in Singapore, aged 25-65 years upon enrolment, and have a child aged 7-11 years who was willing to participate. We focused on parents who were fulltime employees as this is a particularly inactive group in Singapore [16]. Both parent and child had to be able to climb $\geq 10$ stair steps without stopping to minimize health concerns with participation. They also had to be willing to wear an activity tracker throughout the study and an accelerometer for 7 days each at baseline, month 6 , and month 12. At baseline, all participants were required to provide $\geq 600 \mathrm{~min} /$ day of accelerometer wear time on at least 3 weekdays and 1 weekend day out of the 7 days before they were allowed to participate in the study.

Eligible parents wishing to participate signed an informed consent form, assented to their child's participation, and paid a non-refundable enrolment fee of SGD25 $(\approx \mathrm{USD} 18.00)$. The nominal enrolment fee served as a deterrent to those who may join the study solely to receive the free activity tracker but who are not truly motivated to change their behavior. Those who answered 'yes' to any of the 7 Physical Activity Readiness Questionnaire questions, had a body mass index (BMI) of $>40 \mathrm{~kg} / \mathrm{m}^{2}$, asthma, chronic obstructive pulmonary disease, diabetes mellitus, hypertension, lipid disorders, stroke, or personal or familial history of cardiovascular conditions were required to obtain written approval from a physician prior to enrolment. 


\section{Randomization}

After completing enrolment, parent-child dyads were randomized with equal probability into one of two arms (Fig. 1, CONSORT flow diagram) within strata using a computer algorithm with strata defined by low or high amounts of weekly self-reported physical activity. Those who self-reported less than $60 \mathrm{~min} /$ week of moderate-to-vigorous physical activity (MVPA) were classified as low physical activity participants. A statistician generated the randomization list and did not disclose the allocation sequence to the study team members (research assistants/associates) involved in enrolling participants, revealing arm allocation, and delivering the interventions. For allocation concealment, sequentially numbered, opaque, and sealed randomization envelopes was used for the randomization assignment for all participants.

\section{Intervention}

Upon enrolment, all participants were provided with booklets covering the benefits of and strategies for increasing physical activity, encouraged to achieve $\geq 10,000$ steps/day (step target), and issued an activity tracker (Fitbit Zip ${ }^{\circ}$ for children and a Fitbit Flex ${ }^{\circ}$ for parents). The child's activity tracker could be upgraded to a Fitbit Flex ${ }^{\oplus}$ for an additional SGD20 ( $\sim$ USD14.40). Participants also had access to all features available on the Fitbit app and website.

\section{Child-based incentive arm}

Children in the child-based study arm were awarded SGD5 ( $\approx$ USD3.60) each week that they achieved the target through logging their steps on the activity tracker according to the following schedule: $\geq 10,000$ steps/day on $\geq 4, \geq 5$, and $\geq 6$ days each week in months $1-3,4-6$, and

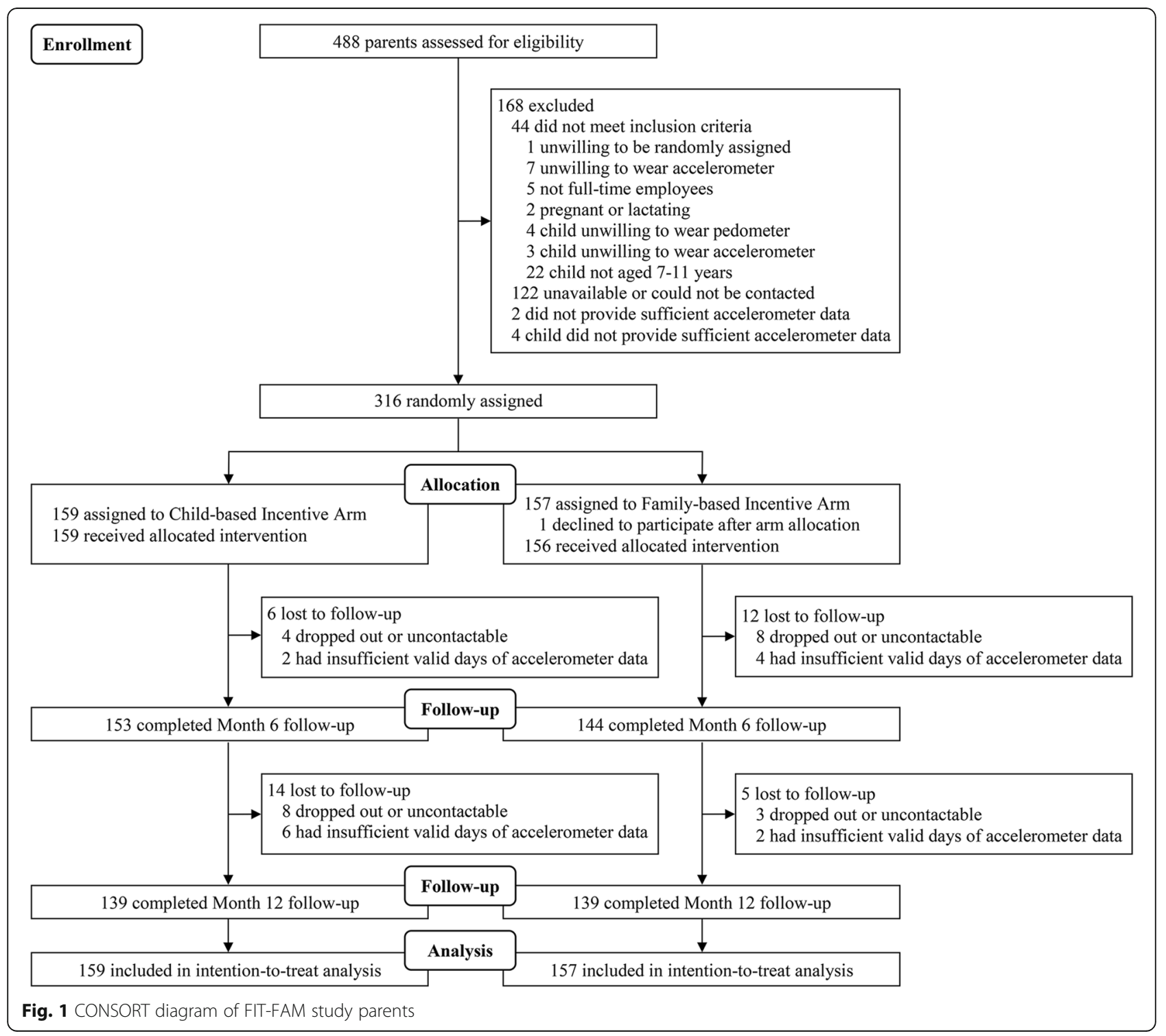


7-12, respectively, and their participating parent logged $\geq 2000$ steps/day on $\geq 4$ days in the same week. The very low threshold for child-based parents, was meant to motivate child-based parents to wear the activity tracker. Children in the child-based arm could also earn a SGD5 $(\approx \mathrm{USD} 3.60)$ monthly bonus if they and their parents met their respective step targets in all 4 weeks in the month. This reinforcement strategy was used to encourage children to maintain streaks in efforts to promote a habit of sustained physical activity.

We chose a 10,000 steps/day target for simplicity, because this is an often-recommended target [17] and because it is the level advocated on the Fitbit app used by study participants [9]. Increasing the number of days required to reach the step goal throughout the study further encouraged participants to increase physical activity over time.

We chose the amount of SGD5 ( $\approx$ USD3.60) for the weekly and monthly bonus incentives based on a prior study where children were rewarded a comparable amount for achieving monthly physical activity targets [10] and to accommodate the smallest voucher denomination carried by some providers. The maximum payout possible per child (in either arm) was valued at SGD300 ( $\approx$ USD216) over 12 months (48 weeks).

\section{Family-based incentive arm}

Family-based children were awarded SGD5 ( $\approx$ USD3.60) each week that they and their participating parent achieved the same step target schedule presented to children in the child-based study arm through logging their steps on their activity trackers. Family-based children were also eligible to earn the monthly bonus if they and their participating parent met the goal in all weeks in the month.

For both arms, if either child or parent did not reach their weekly goal, the child earned no incentive for that week. Pay-outs were disbursed as child-friendly gift vouchers (e.g., Toys"R”Us).

\section{Outcomes and assessments}

Step-tracking and awarding of incentives were based on the Fitbit activity trackers provided upon enrolment. However, to ensure higher quality data and to minimize missingness, the outcome of interest was the betweenarm difference in the change in parents' steps/day at months 6 and 12 (month 12 as primary endpoint) relative to baseline measured using waist-worn triaxial GT3X+ or wGT3X-BT ActiGraph accelerometers. Accelerometry was also used to measure the following secondary outcomes: steps/day (children); MVPA and MVPA bouts; sedentary duration; light, moderate, and vigorous physical activity; and total volume of physical activity (sum of light, moderate, and vigorous physical activity) presented in average minutes/day. Accelerometer data were expressed as average vector magnitude (VM) counts per minute (cpm). Tri-axial VM cut-points classified time in sedentary $(0-199 \mathrm{cpm})$, light (200$2689 \mathrm{cpm})$, moderate $(2690-6166 \mathrm{cpm})$, and vigorous $(\geq 6167 \mathrm{cpm})$ minutes/day [18, 19]. MVPA was defined as VM $\geq 2690 \mathrm{cpm}$. MVPA bouts were defined as a total of 10 or more consecutive minutes above the MVPA VM cut-point with allowance for interruptions of 1 or 2 min below the cut-point [20]. The Choi et al. algorithm was used to identify adherent days [21]. A sample rate of $30 \mathrm{~Hz}$ and an epoch duration of $60 \mathrm{~s}$ were specified.

Participants were encouraged to wear the accelerometer on their waist for 7 days during waking hours at each assessment period, regardless of whether they wore their activity tracker during follow-up. Similar to the baseline assessment, data were considered adherent if $\geq 3$ weekdays and 1 weekend day were provided for $\geq 600$ $\mathrm{min}$ /day of wear time during each follow-up assessment period. All data were processed with $\mathrm{R}$ (version 3.5.1).

Secondary health outcomes for parents include BMI (Seca 217 Portable Stadiometer and Seca 869 Floor Scale), systolic blood pressure (Welch Allyn Spot Vital Signs Blood Pressure monitor), estimated cardiorespiratory fitness [maximum oxygen consumption $\left(\mathrm{VO}_{2 \max }\right)$ approximated based on age, gender, BMI, resting heart rate (Welch Allyn Spot Vital Signs Blood Pressure monitor), and a non-exercise test (NET-F) for cardiorespiratory fitness; termed NET-F $\left.\mathrm{VO}_{2 \max }\right][22,23]$, and healthrelated quality of life (EQ-5D-5L) using the Thailand EQ-5D-5L value set as no Singapore value set was available [24]). All health outcome measures, excluding those collected through online questionnaires, were obtained at Duke-NUS Medical School or at the company worksites. Covariates (age, gender, and ethnicity) were captured at baseline and potential moderators were captured at baseline and both follow-up assessments using online questionnaires. For moderators, family dynamics were measured using the Family Adaptability and Cohesion Scale (FACES IV) [25], and parents' social support for and enjoyment of physical activity were measured by the Physical Activity and Social Support scale (PASS) [26, 27] and the Physical Activity Enjoyment Scale (PACES), respectively [28]. To encourage attendance and questionnaire completion, parents were compensated SGD20 ( $\approx$ USD14.40) per completed follow-up assessment.

\section{Sample size calculation}

The study was powered to detect a medium effect size (r) of 0.3 between family-based and child-based parents assuming $20 \%$ attrition at month 12 . We chose to power the study on a medium effect size so any differences observed would be both clinically meaningful and 
statistically significant. We were guided by effect sizes of this magnitude based on our prior studies $[9,10]$. Using this effect size, an alpha of 0.05 , and power of 0.8 , we needed 158 parent-child dyads per arm.

\section{Statistical analysis}

We hypothesized that the family-based incentive scheme would be more effective at increasing steps at months 6 and 12 (primary) [hypothesis $(\mathrm{H}) 1$ ] and other measures of physical activity and health outcomes (H2) among parents without reducing children's physical activity (H3). We also hypothesized that parents in the familybased incentive scheme would be more likely to achieve the weekly step targets (goal attainment) over the course of the study (H4).

We used a mixed effects linear difference-in-differences regression to test our primary hypothesis $(\mathrm{H} 1)$ on parents with the key dependent variable being the number of daily steps recorded for person $i$ on day $j$ as measured by the accelerometer during each assessment. Independent variables include time and treatment (family-based participants) dummies and their interactions, controls for age, gender, and ethnicity. We also include fixed effects for worksites, random effects for individual participants, and adjusted the standard errors for clustering within individuals across days. Tests of our hypotheses were the sign and significance of the interaction terms, which allowed for testing whether step changes from baseline at months 6 and 12 (primary) were greater for family-based than child-based parents.

Analogous regressions were run for secondary hypotheses with the exception of H4. This hypothesis was tested with separate mixed effects logistic regression models for each incentive period where the dependent variable is an indicator variable for whether the $\geq 10,000$ steps/day target was achieved and the key independent variable is a dummy for family-based participants. This variable allowed for testing whether those in the familybased arm were more likely to achieve the $\geq 10,000$ steps/day targets in each incentive period. The logistic regressions included the same controls, and fixed and random effects as the linear model. Finally, we explored several potential moderators of effectiveness, including parent's and child's gender, family dynamics, and parent's social support for and enjoyment of physical activity as described in Additional file 2. All analyses were from the intent-to-treat basis and conducted in Stata (version 14.2).

\section{Results}

\section{Participant characteristics}

Overall, 316 dyads were recruited from January 2016 to July 2017, of which 159 were randomly assigned to the child-based arm and 157 to the family-based arm (Fig. 1,
CONSORT flow diagram). Parents were on average 42 years old (SD: 4.4) and 57.0\% were male (Table 1). The majority were Chinese (75.3\%), college graduates or postgraduates $(85.4 \%)$, and, among those who declared, had monthly household incomes of $\geq$ SGD10,000 $(\approx \mathrm{USD} 7,198)(31.1 \%)$. Children were on average 9 years old (SD: 1.4 ) and $54.8 \%$ were male.

At baseline, parents in both arms exhibited similar numbers of steps/day with child-based and family-based parents logging 8425 (SD: 2807.1) and 8250 (SD: 2564.9) steps/day as measured via accelerometry (Table 2). All other measures of parents' physical activity and health outcomes were also similar across arms (Table 2).

Six (3.8\%) parents in the child-based and $12(7.7 \%)$ in the family-based arm were lost to follow-up at month 6 . Twenty (12.6\%) parents in the child-based and 17 $(10.8 \%)$ in the family-based arms were lost to follow-up at month 12 (Fig. 1).

\section{Steps logged and goal attainment as measured by the activity tracker}

Figure $2 \mathrm{a}$ and $\mathrm{b}$ show average steps/day logged on the activity tracker by week over 48 weeks for parents and children, respectively. Child-based parents and familybased parents logged on average 8955 steps/day, and 10, 645 steps/day, respectively. Child-based and familybased children logged similar average steps/day of 10 , 772 and 10,793, respectively.

Fig. $2 \mathrm{c}$ and $\mathrm{d}$ show the percentage of parents and children meeting the step targets according to the $\geq 10,000$ steps/day schedule by week over 48 weeks. Child-based parents met the target steps for 37,23 , and $21 \%$ of the possible weeks in months $1-3,4-6$, and 7-12, respectively. These same measures for meeting the target steps were higher $(79,67$, and $55 \%$, respectively) for parents in the family-based arm. Logistic regression results indicated statistically significant differences across all three incentive periods (Additional file 3) consistent with H4. Children in the child-based arm met the step target for 75,65 , and $55 \%$ of the possible weeks in months $1-3,4-6$, and 7-12, respectively. These same measures for meeting the target steps were similar to those of children in the family-based arm at 77,67 , and $57 \%$, respectively. Logistic regression results revealed no statistically significant differences between the two arms (Additional file 4).

On average, children in the child-based and familybased arm earned SGD11.51 ( $\approx$ USD8.29) and SGD11.30 ( USD8.13) per month, respectively, over the 12-month incentive period.

\section{Parents' outcomes}

Regression results based on accelerometry at each assessment period are shown in Table 3. Wear time was not statistically different across arms (Additional file 5). 
Table 1 Participants' baseline characteristics by study arm

\begin{tabular}{|c|c|c|c|}
\hline Participant characteristics & $\begin{array}{l}\text { All } \\
\text { Participants } \\
(n=316)\end{array}$ & $\begin{array}{l}\text { Child-Based Incentive } \\
(n=159)\end{array}$ & $\begin{array}{l}\text { Family-Based Incentive } \\
(n=157)\end{array}$ \\
\hline Parents' age, years, mean (SD) & $42.0(4.4)$ & $42.0(4.4)$ & $42.1(4.5)$ \\
\hline Children's age, years, mean (SD) & $9.0(1.4)$ & $9.0(1.4)$ & $9.0(1.4)$ \\
\hline \multicolumn{4}{|l|}{ Parents' sex, no. (\%) } \\
\hline Male & $180(57.0)$ & $92(57.9)$ & $88(56.1)$ \\
\hline \multicolumn{4}{|l|}{ Children's sex, no. (\%) } \\
\hline Male & $173(54.8)$ & $94(59.1)$ & $79(50.3)$ \\
\hline \multicolumn{4}{|l|}{ Parents' ethnicity, no. (\%) } \\
\hline Chinese & $238(75.3)$ & $120(75.5)$ & $118(75.2)$ \\
\hline Malay & $4(1.3)$ & $3(1.9)$ & $1(0.6)$ \\
\hline Indian & $62(19.6)$ & $31(19.5)$ & $31(19.8)$ \\
\hline Other & $12(3.8)$ & $5(3.1)$ & $7(4.5)$ \\
\hline \multicolumn{4}{|l|}{ Parents' education, no. (\%) } \\
\hline High school or lower & $3(1.0)$ & $0(0.0)$ & $3(1.9)$ \\
\hline Diploma or professional qualification & $43(13.7)$ & $15(9.4)$ & $28(17.8)$ \\
\hline College graduate or higher & $269(85.4)$ & $143(89.9)$ & $126(80.3)$ \\
\hline \multicolumn{4}{|l|}{ Monthly household income, no. (\%) } \\
\hline$<\mathrm{SGD} 5,000$ & $35(11.1)$ & $17(10.7)$ & $18(11.5)$ \\
\hline SGD5,000-SGD9,999 & $94(29.8)$ & $52(32.7)$ & $42(26.8)$ \\
\hline$\geq$ SGD10,000 & $98(31.1)$ & $47(29.6)$ & $51(32.5)$ \\
\hline Don't know & $3(1.0)$ & $0(0.0)$ & $3(1.9)$ \\
\hline Prefer not to say & $85(27.0)$ & $42(26.4)$ & $43(27.4)$ \\
\hline
\end{tabular}

Table 2 Parents' mean (SD) baseline measures by study arm

\begin{tabular}{|c|c|c|c|}
\hline & $\begin{array}{l}\text { All Participants } \\
(n=316)\end{array}$ & $\begin{array}{l}\text { Child-Based Incentive } \\
(n=159)\end{array}$ & $\begin{array}{l}\text { Family-Based Incentive } \\
(n=157)\end{array}$ \\
\hline \multicolumn{4}{|c|}{ Average Baseline Levels of Accelerometry Measures } \\
\hline Steps/day & $8338(2693.0)$ & $8425(2807.1)$ & $8250(2564.9)$ \\
\hline $\mathrm{MVPA}^{\mathrm{a}} \mathrm{min} / \mathrm{day}$ & $44.8(24.5)$ & $45.6(24.4)$ & $43.9(24.5)$ \\
\hline MVPA ${ }^{a}$ bout min/ day & $16.9(18.6)$ & $17.7(18.7)$ & $16.2(18.4)$ \\
\hline Sedentary behavior min/day & $526.4(108.4)$ & $523.0(107.4)$ & $529.8(109.2)$ \\
\hline Light physical activity min/day & $302.6(82.4)$ & $303.6(88.2)$ & $301.7(75.9)$ \\
\hline Moderate physical activity min/day & $42.0(22.7)$ & $42.8(22.2)$ & $41.3(23.2)$ \\
\hline Vigorous physical activity min/day & $2.7(5.1)$ & $2.8(5.6)$ & $2.6(4.7)$ \\
\hline Total volume of physical activity ${ }^{b}$ min/day & $347.3(86.3)$ & $349.2(93.5)$ & $345.6(78.3)$ \\
\hline \multicolumn{4}{|l|}{ Average Baseline Levels of Health Measures } \\
\hline Body mass index $\left(\mathrm{kg} / \mathrm{m}^{2}\right)$ & $24.4(3.6)$ & $24.2(3.7)$ & $24.5(3.5)$ \\
\hline Systolic blood pressure (mm Hg) & $115.1(17.0)$ & 115.5 (17.7) & 114.7 (16.2) \\
\hline NET-F VO ${ }_{2 \max }{ }^{c}$ & 30.7 (3.6) & $31.0(3.6)$ & $30.5(3.5)$ \\
\hline EQ-5D Index ${ }^{d}$ & $0.95(0.09)$ & $0.96(0.08)$ & $0.95(0.10)$ \\
\hline
\end{tabular}

${ }^{a}$ MVPA is moderate-to-vigorous physical activity ${ }^{\mathrm{b}}$ Total volume of physical activity is the sum of light, moderate, and vigorous physical activity minutes

${ }^{c} \mathrm{NET}-\mathrm{F} \mathrm{VO}_{2 \max }$ is a measure of cardiorespiratory fitness assessed without lab-based exercise

${ }^{d}$ EQ-5D is a standardized means of measuring health-related quality of life 


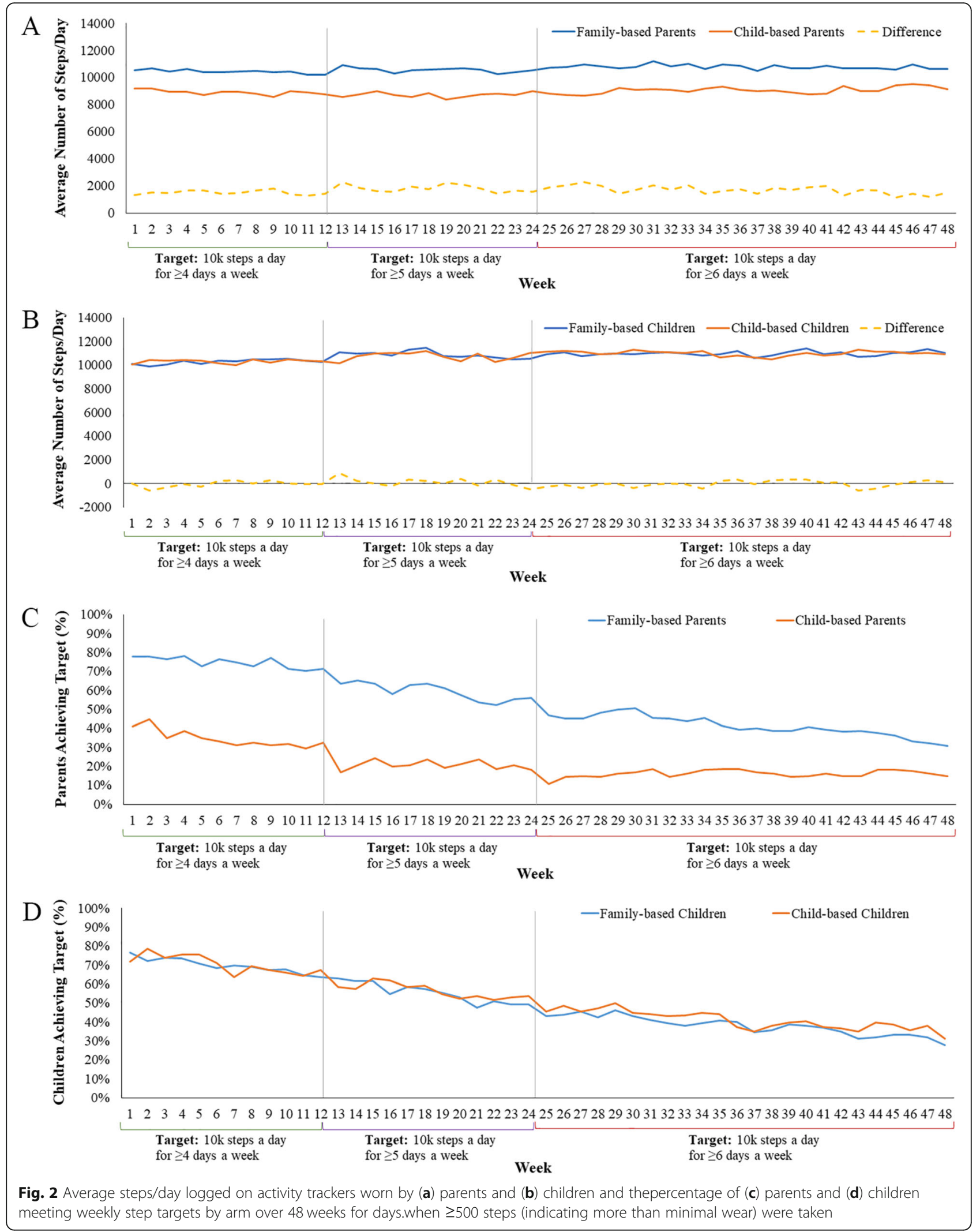


Table 3 Difference $(95 \% \mathrm{Cl})$ in parents' accelerometer-derived outcomes at months 6 and $12^{\text {a }}$

\begin{tabular}{|c|c|c|c|}
\hline & \multicolumn{2}{|c|}{ Difference from Baseline, by Study Arm } & \multirow{2}{*}{$\begin{array}{l}\text { Between-arm Comparisons } \\
\text { Family-Based Incentive vs } \\
\text { Child-Based Incentive }\end{array}$} \\
\hline & $\begin{array}{l}\text { Child-Based Incentive } \\
(n=159)\end{array}$ & $\begin{array}{l}\text { Family-Based Incentive } \\
(n=157)\end{array}$ & \\
\hline \multicolumn{4}{|l|}{ MONTH 6} \\
\hline Steps/day & $-379(-778,19)$ & $234(-157,624)$ & $613^{*}(54,1171)$ \\
\hline MVPA $^{\text {b }}$, min/day & $-0.2(-4.4,3.9)$ & $2.8(-0.7,6.2)$ & $3.0(-2.4,8.4)$ \\
\hline MVPA $^{b}$ bouts, min/day & $0.0(-3.2,3.1)$ & $3.5^{*}(0.5,6.5)$ & $3.5(-0.8,7.9)$ \\
\hline Sedentary behavior, min/day & $8.6(-7.7,25.0)$ & $12.9(-4.1,29.8)$ & $4.2(-19.3,27.7)$ \\
\hline Light physical activity, min/day & $-12.9(-27.4,1.7)$ & $-15.8^{* *}(-27.2,-4.3)$ & $-2.9(-21.4,15.6)$ \\
\hline Moderate physical activity, min/day & $0.2(-3.5,4.0)$ & $2.4(-0.8,5.5)$ & $2.1(-2.8,7.0)$ \\
\hline Vigorous physical activity, min/day & $-0.5(-1.3,0.4)$ & $0.4(-0.7,1.5)$ & $0.9(-0.5,2.2)$ \\
\hline Total volume of physical activity, min/day & $-13.1(-28.9,2.7)$ & $-13.0^{*}(-25.1,-0.9)$ & $-0.1(-19.8,20.0)$ \\
\hline \multicolumn{4}{|l|}{ MONTH 12} \\
\hline Steps/day & $-208(-620,203)$ & $160(-219,539)$ & $369(-191,928)$ \\
\hline $\mathrm{MVPA}^{\mathrm{b}}$, min/ day & $0.7(-3.6,5.1)$ & $2.9(-0.5,6.3)$ & $2.2(-3.4,7.7)$ \\
\hline 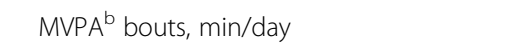 & $0.6(-2.6,3.8)$ & $2.4(-0.3,5.2)$ & $1.8(-2.4,6.1)$ \\
\hline Sedentary behavior, min/day & $11.8(-6.6,30.3)$ & $13.2(-6.7,33.2)$ & $1.4(-25.7,28.5)$ \\
\hline Light physical activity, min/ day & $-14.5^{*}(-28.7,-0.2)$ & $-16.5^{* *}(-28.8,-4.3)$ & $-2.1(-20.9,16.7)$ \\
\hline Moderate physical activity, min/day & $0.8(-3.1,4.7)$ & $2.1(-1.0,5.2)$ & $1.3(-3.7,6.3)$ \\
\hline Vigorous physical activity, min/day & $0.01(-1.0,1.0)$ & $0.8(-0.1,1.6)$ & $0.8(-0.5,2.1)$ \\
\hline Total volume of physical activity ${ }^{\complement}, \mathrm{min} /$ day & $-13.7(-28.4,1.1)$ & $-13.6^{*}(-26.5,-0.8)$ & $0.0(-19.6,19.6)$ \\
\hline
\end{tabular}

${ }^{a}$ Unadjusted for wear time since wear time was comparable across arms ${ }^{b}$ MVPA is moderate-to-vigorous physical activity ${ }^{c}$ Total volume of physical activity is the sum of light, moderate, and vigorous physical activity minutes Note: * $p<0.05,{ }^{* *} p<0.01,{ }^{* * *} p<0.001$

At month 6, family-based parents increased their steps/ day by 234 steps (95\% CI: - 157-624) relative to baseline, whereas child-based parents decreased their steps/ day by 379 steps (95\% CI: -778-19). Consistent with H1, family-based parents had a positive and statistically significant step differential of 613 steps/day (95\% CI: 541171) compared to child-based parents at month 6 . Adjusting for wear time did not change the direction or significance of this result.

At month 12, our primary endpoint, the family-based parents increased their steps/day by 160 steps (95\% CI: - 219-539) relative to baseline whereas child-based parents decreased their steps/day by 208 steps (95\% CI: 620-203). However, the differential of 369 steps/day (95\% CI: - 191-928), our primary outcome, was no longer statistically significant and inconsistent with $\mathrm{H} 1$. None of the secondary accelerometry-based measures (Table 3) nor any of the health outcomes (Table 4) were statistically different across arms at months 6 or 12, inconsistent with $\mathrm{H} 2$.

\section{Children's outcomes}

Additional file 6 presents children's accelerometer results. At month 6, relative to baseline, family-based children achieved a statistically significant increase of 464 steps/day (95\% CI: 34-895), whereas children in the child-based study arm logged a decrease of 8 steps/day (95\% CI: - 445-428), resulting in a statistically nonsignificant differential of 473 steps/day (95\% CI: - 1391085) between the two arms.

At month 12, relative to baseline, family-based children logged an increase of 315 steps/day (95\% CI: 131-761), while children in the child-based study arm logged an increase of 254 steps/day (CI: - 184-693), for a non-statistically significant differential of 61 steps/day (95\% CI: - 565-686). Results for other children's outcomes were also not statistically different across arms (Additional file 6). Hence, consistent with $\mathrm{H} 3$, the family-based incentive did not negatively affect the physical activity of children in the family-base arm.

\section{Potential moderators}

Neither gender, social support for physical activity, family dynamics, nor enjoyment of physical activity moderated the effectiveness of the family-based incentives on steps (Additional file 7).

\section{Discussion}

Prior studies have shown that incentives have been used successfully to influence health behaviors of the incentive target, ranging from physical activity, which is the focus of this effort, to smoking cessation, weight loss, 
Table 4 Difference $(95 \% \mathrm{Cl})$ in parent's health outcomes at months 6 and 12

\begin{tabular}{|c|c|c|c|}
\hline & \multicolumn{2}{|c|}{ Difference from Baseline, by Study Arm } & \multirow{2}{*}{$\begin{array}{l}\text { Between-arm Comparisons } \\
\text { Family-Based Incentive vs } \\
\text { Child-Based Incentive }\end{array}$} \\
\hline & Child-Based Incentive $(n=159)$ & Family-Based Incentive $(n=157)$ & \\
\hline \multicolumn{4}{|l|}{ MONTH 6} \\
\hline Body mass index $\left(\mathrm{kg} / \mathrm{m}^{2}\right)$ & $0.0(-0.1,0.1)$ & $0.0(-0.1,0.1)$ & $0.0(-0.1,0.2)$ \\
\hline Systolic blood pressure (mm Hg) & $-1.1(-2.7,0.4)$ & $-1.7^{*}(-3.1,-0.3)$ & $-0.6(-2.6,1.5)$ \\
\hline NET-F VO ${ }_{2 \max }{ }^{a}$ & $-0.1(-0.2,0.1)$ & $-0.1^{*}(-0.2,0.0)$ & $0.0(-0.2,0.1)$ \\
\hline Change in EQ-5D Index ${ }^{b}$ & $0.016^{*}(0.002,0.031)$ & $0.001(-0.015,0.018)$ & $-0.015(-0.037,0.007)$ \\
\hline \multicolumn{4}{|l|}{ MONTH 12} \\
\hline Body mass index $\left(\mathrm{kg} / \mathrm{m}^{2}\right)$ & $0.2^{*}(0.0,0.3)$ & $0.2^{* *}(0.0,0.3)$ & $0.0(-0.2,0.2)$ \\
\hline Systolic blood pressure (mm Hg) & $-1.1(-2.9,0.7)$ & $-0.7(-2.3,0.9)$ & $0.4(-2.0,2.8)$ \\
\hline NET-F VO ${ }_{2 \max }{ }^{a}$ & $-0.2^{* * *}(-0.3,-0.1)$ & $-0.2^{* *}(-0.3,-0.1)$ & $0.0(-0.1,0.2)$ \\
\hline Change in EQ-5D Index ${ }^{b}$ & $-0.009(-0.025,0.008)$ & $-0.011(-0.026,0.005)$ & $-0.002(-0.024,0.021)$ \\
\hline
\end{tabular}

${ }^{\mathrm{a}} \mathrm{NET}-\mathrm{F} \mathrm{VO}_{2 \max }$ is a measure of cardiorespiratory fitness assessed without lab-based exercise

${ }^{b}$ EQ-5D is a standardized means of measuring health-related quality of life

Note: ${ }^{*} p<0.05,{ }^{* *} p<0.01,{ }^{* * *} p<0.001$

medication adherence, and others. Classical economic theory posits that incentives can be effective to influence health behaviors, as long as the size of the incentive is large enough such that the expected benefits outweigh the costs of the behavior change. Behavioral economists and psychologists argue that it is not just the size of incentives that matters. They posit that, due to the presence of cognitive biases, many design features are likely to influence effectiveness, including type, frequency, and duration of incentive payments, and that taking advantage of these factors can increase effectiveness [29]. There is an additional literature arguing that group based incentives may work better than individual incentives under the assumption that members will work harder to obtain a goal so as not to let down the other group members [30]. However, this strategy tends to outperform individual incentives only if group members act pro-socially (i.e., they care about the other group members), their behavior is easily observable, and if they believe that their behavior will influence the behavior of others, suggesting it is likely to work best for small tightly knit groups. There is some evidence supporting this approach $[13,31]$.

This study takes the group based incentive strategy a step further. Because parents are expected to act prosocially in support of their child's physical activity levels, we hypothesized that extending a proven incentive strategy to both the child (target) and parent's (affiliate) physical activity could be effective even if the parent only indirectly benefits and/or does not want to bear the 'cost' of disappointing their child. Such a strategy has not been tested previously.

Our findings provide only suggestive evidence consistent with this hypothesis. Our primary outcome of parents' steps/day at 12 months was slightly greater for parents in the parent-based arm but not statistically different across arms, nor were any of the secondary accelerometry-based measures or health outcomes variables significantly different. However, at month 6 , family-based parents had a positive step differential of 613 steps/day (95\% CI: 54-1171) compared to childbased parents. Moreover, throughout the entire study, family-based parents were statistically and far more likely to reach the weekly step target than child-based parents. This suggests that that parents were changing their behavior as a result of the incentive design. There is no evidence that the design negatively affects children's behavior.

The lack of more compelling results does not condemn such a strategy. As noted earlier, classical economic theory suggests that incentives can be effective to influence health behaviors, not that they will be in all cases. Incentives need to be large enough such that that the expected benefit is greater than the expected cost. The behavioural economics literature offers additional stipulations [15]. Therefore, it is not surprising that although many studies have shown that incentives work to change health behaviours, there is also a large body of literature showing cases where they do not [29].

In our case, several factors may explain the lack of statistically significant step increases at month 12 , our primary endpoint. Although we cannot rule out that parents do not act pro-socially when it comes to their children's health, it may be that design features led to a lack of effectiveness of our primary outcome. For example, a larger incentive may have led to greater changes in behavior. Alternatively, had we kept the step target unchanged between months 6 and months 12 (i.e., $\geq 10,000$ steps/day on $\geq 5$ days/week) and/or increased the reward value, the month 6 results might have been 
sustained. In fact, waning effectiveness of incentives over time for health behavior change is not unique to this study [29]. Changing behavior to improve health is difficult and maintaining those changes has proven to be even more difficult, suggesting that a larger reward may be necessary to sustain any changes in behavior that occur in the short term as a result of incentives. Finally, although we measured clinical health improvements, it is possible that even if our primary outcome were statistically significant, a specific duration and intensity of physical activity would be required to translate into clinically relevant health improvements. Without these improvements, it will be difficult to justify the value of any incentive-based program to funders. All of these factors should be considered in the design of future studies. Future research could also explore differential effects by socioeconomic status. Low socioeconomic status individuals may be more motivated by the prospect of a reward but may also be more constrained in their ability to adjust their behavior.

\section{Strengths and limitations}

The primary strength of this study was testing our novel incentive design via a 12-month RCT. Other strengths include using accelerometers to measure the primary outcome, two assessment time points, and a low attrition rate of $12 \%$ at our primary endpoint.

The primary weakness of our approach is that whereas positive results provide evidence consistent with the theory, negative results are more difficult to interpret; does one reject the theory or the incentive design? Our design is one of endless possible reward strategies. Although we relied on incentive levels successfully employed in a prior study and incentive targets consistent with recommendations, it is certainly possible that an alternative design might have produced superior results.

Other limitations include the use of Fitbit models that do not detect wear time and the use of identical cutpoints for children and adults when classifying activity levels into light, moderate, and vigorous physical activity. Although some studies use different cut-points for children and adults, the fact that the activity tracker and accelerometer generated the same conclusions for children (i.e., no differences across arms), we do not see this as a significant concern. Finally, our study is based on an educated sample recruited in Singapore, a fairly walkable city-state but one that is hot and humid, so whether or not these results would replicate in other populations or locations is unknown.

\section{Conclusions}

There is growing interest in identifying low-cost incentive strategies that can be used to reduce risk factors for chronic disease. Our findings suggest that novel incentive designs that take advantage of group dynamics may be effective. However, in this particular design, the effectiveness of the family-based incentive to increase parent's physical activity was not sustained at the one-year followup period.

\section{Supplementary information}

Supplementary information accompanies this paper at https://doi.org/10. 1186/s12966-020-01018-2.

Additional file 1. CONSORT checklist.

Additional file 2. Moderation analysis methods.

Additional file 3. Mixed effects logistic regressions - parents (odds ratios, 95\% Cl).

Additional file 4. Mixed effects logistic regressions - children (odds ratios, 95\% Cl).

Additional file 5. Parental and child average accelerometer wear time (min/day) by study arm.

Additional file 6. Difference $(95 \% \mathrm{Cl})$ in child accelerometer-derived outcomes at months 6 and 12 (unadjusted for wear time since wear time was comparable across arms).

Additional file 7. Moderation analysis results

Additional file 8. Pearson correlation analysis between accelerometerlogged steps and activity tracker-logged steps.

\section{Abbreviations}

BMI: Body mass index; cpm: Counts per minute; EQ-5D-5L: Health-related quality of life; FACES IV: Family Adaptability and Cohesion Scale; MVPA: Moderate-to-vigorous physical activity; NET-F: Non-exercise test for fitness; PACES: Physical Activity Enjoyment Scale; PASS: Physical Activity and Social Support scale; RCT: Randomized controlled trial; VM: Vector magnitude; $\mathrm{VO}_{2 \text { max }}$ : Maximum oxygen consumption

\section{Acknowledgements}

We thank Yubing Tian for data analysis and for preparing the initial manuscript drafts.

\section{Authors' contributions}

EAF was the principal investigator and conceived the study. EAF, DSW, and KRE designed the study. RLSM was involved in study implementation and data acquisition. EAF, RLSM, DSW, and KRE contributed to the interpretation of the results and critically read and edited several drafts of the manuscript before submission. All authors read and approved the submitted version.

\section{Funding}

This study was supported by a Health Services Research Competitive Research Grant (HSRG/0048/2015) from the National Medical Research Council (NMRC), Ministry of Health, Singapore. NMRC had no role in the study design and implementation, data collection and analysis, interpretation of the results, manuscript preparation, or decision to publish. The study did not involve any partnership with Fitbit.

\section{Availability of data and materials}

De-identified data will be made available upon reasonable request to the corresponding author. An investigator who proposes to use the data must have approval from an Institutional Review Board, Independent Ethics Committee, or Research Ethics Board, as applicable, and execute a data use/ sharing agreement with Duke-NUS Medical School.

Ethics approval and consent to participate Ethics approval was granted by the National University of Singapore Institutional Review Board (Approval Number: NUS 2592). All parents signed informed consent and assented to their child's participation. 


\section{Competing interests}

We declare no competing interests.

\section{Author details}

'Programme in Health Services and Systems Research, Duke-NUS Medical School, 8 College Road, Singapore 169857, Singapore. ${ }^{2}$ Center for Health Promotion and Disease Prevention, University of North Carolina Chapel Hill, 1700 Martin Luther King Jr. Boulevard \#7426, Chapel Hill, NC 27514, USA. ${ }^{3}$ Department of Nutrition, Gillings School of Global Public Health, University of North Carolina Chapel Hill, 135 Dauer Drive, Chapel Hill, NC 27599, USA. ${ }^{4}$ Department of Epidemiology, Gillings School of Global Public Health, University of North Carolina Chapel Hill, Chapel Hill, NC 27599-8050, USA.

Received: 7 April 2020 Accepted: 3 September 2020

Published online: 10 September 2020

\section{References}

1. Ding D, Kolbe-Alexander T, Nguyen B, Katzmarzyk PT, Pratt M, Lawson KD. The economic burden of physical inactivity: a systematic review and critical appraisal. Br J Sports Med. 2017;51(19):1392-409.

2. Lee IM, Shiroma EJ, Lobelo F, Puska P, Blair SN, Katzmarzyk PT. Effect of physical inactivity on major non-communicable diseases worldwide: an analysis of burden of disease and life expectancy. Lancet. 2012;380(9838): 219-29

3. Guthold R, Stevens GA, Riley LM, Bull FC. Worldwide trends in insufficient physical activity from 2001 to 2016: a pooled analysis of 358 populationbased surveys with 1.9 million participants. Lancet Global Health. 2018;6(10): e1077-e86.

4. Ding D, Lawson KD, Kolbe-Alexander TL, Finkelstein EA, Katzmarzyk PT, van Mechelen W, et al. The economic burden of physical inactivity: a global analysis of major non-communicable diseases. Lancet. 2016;388(10051): 1311-24.

5. Mankiw GN. Principles of Economics. 7 ed. MA: Cengage Learning; 2015.

6. Hunter RF, Tang J, Hutchinson G, Chilton S, Holmes D, Kee F. Association between time preference, present-bias and physical activity: implications for designing behavior change interventions. BMC Public Health. 2018;18(1):1388

7. Gruber J, Mullainathan S. Do Cigarette Taxes Make Smokers Happier? In: Ng YK Ho LS, editors. Happiness and Public Policy. London: Palgrave Macmillan; 2006.

8. O'Donoghue T, Rabin M. Doing It Now or Later. Am Econ Rev. 1999;89(1): 103-24.

9. Finkelstein EA, Haaland BA, Bilger M, Sahasranaman A, Sloan RA, Nang EEK, et al. Effectiveness of activity trackers with and without incentives to increase physical activity (TRIPPA): a randomised controlled trial. Lancet Diabetes Endocrinol. 2016;4(12):983-95.

10. Finkelstein EA, Tan YT, Malhotra R, Lee CF, Goh SS, Saw SM. A cluster randomized controlled trial of an incentive-based outdoor physical activity program. J Pediatr. 2013;163(1):167-72 e1.

11. Mitchell MS, Orstad SL, Biswas A, et al. Financial incentives for physical activity in adults: systematic review and meta-analysis. Br J Sports Med. 2019. https://doi.org/10.1136/bjsports-2019-100633 https://pubmed.ncbi. nIm.nih.gov/31092399/. [published online ahead of print, 2019 May 15].

12. Harkins KA, Kullgren JT, Bellamy SL, Karlawish J, Glanz K. A Trial of Financial and Social Incentives to Increase Older Adults\&\#x2019; Walking. Am J Prevent Med. 2017;52(5):e123-e30.

13. Patel MS, Asch DA, Rosin R, Small DS, Bellamy SL, Eberbach $K$, et al. Individual Versus Team-Based Financial Incentives to Increase Physical Activity: A Randomized, Controlled Trial. J Gen Intern Med. 2016;31(7):746-54.

14. Petry NM, Andrade LF, Barry D, Byrne S. A randomized study of reinforcing ambulatory exercise in older adults. Psychol Aging. 2013;28(4):1164-73.

15. Gneezy U, Meier S, Rey-Biel P. When and Why Incentives (Don't) Work to Modify Behavior. J Econ Perspect. 2011;25(4):191-210.

16. Win AM, Yen LW, Tan KH, Lim RB, Chia KS, Mueller-Riemenschneider F. Patterns of physical activity and sedentary behavior in a representative sample of a multi-ethnic South-East Asian population: a cross-sectional study. BMC Public Health. 2015;15:318.

17. Tudor-Locke C, Craig CL, Brown WJ, et al. How many steps/day are enough? For adults. Int J Behav Nutr Phys Act. 2011;8:79. https://doi.org/10.1186/ 1479-5868-8-79. Published 28 Jul 2011.

18. Keadle SK, Shiroma EJ, Kamada M, Matthews CE, Harris TB, Lee IM. Reproducibility of Accelerometer-Assessed Physical Activity and Sedentary Time. Am J Prev Med. 2017;52(4):541-8.
19. Aguilar-Farias N, Brown WJ, Peeters GM. ActiGraph GT3X+ cut-points for identifying sedentary behaviour in older adults in free-living environments. J Sci Med Sport. 2014;17(3):293-9.

20. Troiano RP, Berrigan D, Dodd KW, Masse LC, Tilert T, McDowell M. Physical activity in the United States measured by accelerometer. Med Sci Sports Exerc. 2008;40(1):181-8.

21. Van Domelen DR. Package 'accelerometry' - Functions for Processing Accelerometer Data: CRAN; 2018 [Available from: https://cran.r-project.org/ web/packages/accelerometry/accelerometry.pdf.

22. Jurca R, Jackson AS, LaMonte MJ, Morrow JR Jr, Blair SN, Wareham NJ, et al. Assessing cardiorespiratory fitness without performing exercise testing. Am J Prev Med. 2005;29(3):185-93.

23. Sloan RA, Haaland BA, Leung C, Padmanabhan U, Koh HC, Zee A. Crossvalidation of a non-exercise measure for cardiorespiratory fitness in Singaporean adults. Singapore Med J. 2013:54(10):576-80.

24. Tongsiri S, Cairns J. Estimating population-based values for EQ-5D health states in Thailand. Value Health. 2011;14(8):1142-5.

25. Olson D. FACES IV and the Circumplex Model: validation study. J Marital Fam Ther. 2011;37(1):64-80.

26. Eyler AA, Brownson RC, Rebecaa JD, King AC, Brown D, Sallis JF. Physical activity social support and middle- and older-aged minority women: results from a US survey. Soc Sci Med. 1999;49:781-9.

27. Sallis JF, Grossman RM, Pinski RB, Patterson TL, Nader PR. The Development of Scales to Measure Social Support for Diet and Exercise Behaviors. Prev Med. 1987;16:825-36.

28. Kendzierski D, DeCarlo KJ. Physical activity enjoyment scale: Two validation studies. J Sport Exerc Psychol. 1991;13(1):50-64.

29. Finkelstein EA, Bilger M, Baid D. Effectiveness and cost-effectiveness of incentives as a tool for prevention of non-communicable diseases: A systematic review. Soc Sci Med. 2019;232:340-50.

30. Rabin M. Psychology and Economics. J Econ Literature. 1998;36(1):11-46.

31. Babcock P, Bedard K, Charness G, Hartman J, R H. Letting Down the Team? Social Effects of Team Incentives. J Eur Econ Assoc. 2015:13(5):841-70.

\section{Publisher's Note}

Springer Nature remains neutral with regard to jurisdictional claims in published maps and institutional affiliations.
Ready to submit your research? Choose BMC and benefit from:

- fast, convenient online submission

- thorough peer review by experienced researchers in your field

- rapid publication on acceptance

- support for research data, including large and complex data types

- gold Open Access which fosters wider collaboration and increased citations

- maximum visibility for your research: over $100 \mathrm{M}$ website views per year

At BMC, research is always in progress.

Learn more biomedcentral.com/submissions 